University of Wollongong

Research Online

Faculty of Business - Papers (Archive)

Faculty of Business and Law

2019

Cultural Capital of Recruitment Decision-Makers and its Influence on their Perception of Person-Organisation Fit of Skilled Migrants

Shamika Almeida

University of Wollongong, shamika@uow.edu.au

Marie-France Waxin

American University of Sharjah

Yin Paradies

Deakin University, yinp@unimelb.edu.au

Follow this and additional works at: https://ro.uow.edu.au/buspapers

Part of the Business Commons

Research Online is the open access institutional repository for the University of Wollongong. For further information contact the UOW Library: research-pubs@uow.edu.au 


\title{
Cultural Capital of Recruitment Decision-Makers and its Influence on their Perception of Person-Organisation Fit of Skilled Migrants
}

\begin{abstract}
This article examines how recruitment decision-makers' cultural capital can influence their concerns about the organizational fit of skilled migrants (SM). We used survey data and interviews with Information Technology organizations in Australia. The study highlights the decision-makers' relatively poor understanding of non-western cultures and how it negatively influences their perception of candidates from non-western backgrounds. Furthermore, this study also notes how organisational cultural values and decision-makers' exposure to diverse cultures can influence their assumptions about the value of international qualifications and work experiences. Similarly, it can also influence how they assess the perception of fit based on a candidate's appearance and communication style. Consequently, the cognitive biases and judgements of resource acquisition managers can act as gatekeepers who keep non-western SM out of the organizational resource pool. The article concludes by noting the importance of human resource practices that seek to develop cultural capital of decision-makers.
\end{abstract}

\section{Keywords}

fit, person-organisation, perception, their, skilled, influence, migrants, its, decision-makers, recruitment, capital, cultural

\section{Disciplines \\ Business}

\section{Publication Details}

Almeida, S., Waxin, M. \& Paradies, Y. (2019). Cultural Capital of Recruitment Decision-Makers and its Influence on their Perception of Person-Organisation Fit of Skilled Migrants. International Migration, 57 (1), 318-334. 


\title{
Cultural capital of recruitment decision makers and its influence on their perception of person-organisation fit of skilled migrants
}

\begin{abstract}
This paper examines how recruitment decision-makers' cultural capital can influence their concerns about the organisational fit of skilled migrants. We used survey data and interviews with Information Technology organisations in Australia. The study highlights the decision makers' relatively poor understanding of non-western cultures and how it negatively influences their perception of candidates from non-western backgrounds. Furthermore, this study also notes how organisational cultural values and decision-makers' exposure to diverse cultures can influence their assumptions about the value of international qualifications and work experiences. Similarly, it can also influence how they assess the perception of fit based on a candidate's appearance and communication style. Consequently, the cognitive biases and judgements of resource acquisition managers can act as gatekeepers who keep non-western skilled migrants out of the organisational resource pool. The paper concludes by noting the importance of human resource practices that seek to develop cultural capital of decision-makers.
\end{abstract}

\section{Keywords}

Human capital, recruiters' cultural capital, person-organisation culture fit, recruitment, skilled migrants 


\section{INTRODUCTION}

Australia has a formalised migration program to attract highly skilled migrants (SMs) aimed at combating skill shortages (Chaloff and Lemaitre, 2009; Cameron, 2011). The top 5 countries of origin for General Skilled Migration visas granted include India (21\%), China (20\%), United Kingdom (14\%), Sri Lanka (5\%) and Malaysia (5\%) (Australian Bureau of Statistics, 2011). Despite the rigorous assessment of migrants' qualifications and experiences, skilled immigrants from non-English speaking backgrounds (NESBs) are less successful in finding employment that matches their skills than their English-speaking counterparts who arrive in Australia under the same formal programs (Kostenko, Harris and Zhao, 2012). This results in inequality in employment outcomes, downward career mobility and under use of education and skills of NESB skilled professionals (Al Ariss and Syed, 2011).

Although skilled migrants (SM) originating from non-Western countries are SelfInitiated Expatriates (SIEs) or temporary migrants who have been sponsored by an employer, they are mostly ignored in the SIE literature and consequently the literature does not focus on the career mobility of the non-Western SIE (Al Ariss and Crowley-Henry, 2013). While several studies have examined the cultural capital deficit of migrants (the nondominant group) (Nakhaie and Kazemipur, 2013), there is a lack of research on the cultural capital deficit of dominant culture organisational recruitment decision-makers (RDM) and how this can influence the perceived negative person-organisation fit (P-O fit) of skilled candidates during the recruitment decision-making process. Thus, the purpose of this paper is to identify how cultural capital deficiency among RDMs can hinder the employment of skilled migrants who originate from non-Western Non English Speaking Backgrounds (NESB) in Australia. 


\section{Employers' cultural capital and its influence on recruitment decisions}

According to the Resource Based View (RBV), organisations are conceptualised as bundles of resources which enable them to differentiate themselves by their unique potential (Barney and Arikan, 2017). When an organisation creates internal organisation-based resources that are valuable, unique and inimitable, it creates a sustainable competitive advantage in the market, enabling the success of the organisation (Barney, 1991). In the context of a global economy, organisations need to develop HR and line managers who have the capabilities, skills and knowledge that will enable them to recruit and retain the best global talent into the organisation. Intelligent career theory (ICT), which is based on RBV theory, indicates that organisations cultivate competencies based on 1) knowing why capabilities (which include organisational culture, values and beliefs), 2) organisational know-how capabilities (which include job relevant explicit and implicit skills and knowledge), and 3) knowing whom capabilities (which include the personal relationships inside and outside of firm's networks) (Pfeifer, Sarlijia, and Zekic, 2014). For example, the collective organisational cross-cultural know-how capabilities, having a global world view of the recruitment talent pool, and having access to multi-cultural talent networks can create valuable, unique and inimitable bundles of internal capabilities and resources that can enable an organisation to create a sustainable competitive advantage in the globalised economy. We argue that these unique internal collective resource capabilities can influence the cultural capital of line managers and HR professionals involved in the recruitment decision-making process.

Cultural capital includes the beliefs, attitudes, behaviours and customs (Bourdieu, 1986; 2010) of the line manager or HR professional. This includes the embodied capital (i.e. mannerisms, dress codes and mastery of language which are generally acquired through family and socialisation), the objectified capital (i.e. physical objects that are owned) and the institutionalised capital (academic qualifications and titles) (Bourdieu, 1986; Bourdieu, 
1990). According to Erel (2010) research has mostly looked at migrants' cultural capital from an ethnically bounded angle which assumes that migrants bring a set of 'cultural resources from the country of origin to the country of migration that either fit or do not fit'. However, there seems to be a lack of empirical research that looks at the issue of cultural capital of RDM and how it can support the talent recognition of the migrant talent pool which can originate from cultural backgrounds dissimilar to that of the RDM.

Cultural capital is shaped by the evolving experiences of the organisation's employees (Ibarra, 2003). We argue that, if and when, line managers and HR professionals lack understanding/competence of non-Western cultures and religions due to their lack of experiences with diversity, this can have a negative influence on their recruitment decisionmaking. For instance, the cultural capital deficiency (CCD) of the RDM may be due to the limitations in their knowledge/expertise, personal and professional networks or narrow Westernised perspective of their values and beliefs. This CCD of recruitment decision makers can result in the differential validation of the SM applicants during the recruitment process.

The CCD of RDM can be conditioned by the Western contextual experiences of these managers. For example, according to Bourdieu's theory of human capita (Bourdieu, 1990; Özbilgin and Tatli, 2005), field is the social and structural reality people inhabit and conditions the habitus. Habitus of the RDM are the schema of perceiving, feeling, thinking and acting that guides conscious or unconscious behaviour (habits and biases) which are conditioned by social origins and experiences in the field (Bourdieu, 1990; Özbilgin andTatli, 2005). As such, the unconscious and conscious habits and biases of RDM are heavily influenced by their early experiences in life, with family playing an important role in shaping these. According to Bourdieu, these conscious and unconscious habits and biases can then influence the doxas of the recruitment decision makers (routines and actions that 
are done automatically particularly, within typical Western recruitment processes that are based on taken for granted assumptions about how to select the best candidates). It is possible that these doxas are unfavourable to the selection and hiring of SMs, particularly the NESB SMs who may originate from non-western backgrounds, as the assumptions and behaviours of the Western RDM are likely to favour local candidates who fit within their own habitus and doxas. Consequently, these Western specific habitus and doxa of RDM may be enacted during the recruitment process using their authority and power inherent to their organisational roles.

Symbolic capital refers to the power gained or inherited through accumulation and deployment of economic, cultural and social capital (Bourdieu, 1986). Symbolic capital is linked to power ascribed to individuals due to the legitimate authority they hold for deployment of all other forms of capital (Doherty \& Dickmann, 2009). In the case of RDM, they have the legitimate authority to recruit and select who they think will be valuable to the organisation, and to assign value to the various forms of capital of candidates during the recruitment process. The RDM can use their legitimate role and power in the organisation to decide on who is in, and who is out of the organisation. They can use this symbolic capital to decide which candidates to exclude as the outsiders (migrants) and which candidates are allowed into the elite organisational membership. This then can result in the negative person-organisation fit assessment of SMs during the recruitment process.

\section{Person-organisation fit}

The concept of person-organisation (P-O) fit is defined by Kristof (1996, p. 45) as 'the compatibility between people and organisations that occurs when: (a) at least one entity provides what the other needs, or (b) they share similar fundamental characteristics, or (c) both' (p. 45). P-O fit is a significant issue in the context of global trends such as Brexit and 
Trumpism which demonstrate an underlying need for nationalism coupled with an apprehensive attitude towards migration in Western countries (Korostelina, 2016). Such a mind-set can result in increased levels of stigmatisation and the perception that candidates originating from NESB have low person-organisation fit.

RDM's cultural capital can influence the need to hire candidates who are either similar to them or their organisational clientele (Hebbani and Colic-Peisker, 2012). Perceived similarity enables communication and trust, and promotes behavioural prediction (Sacco Scheu, Ryan and Schmitt, 2003). Attire can heavily influence the perception of similarity transmitted during the interview, as it communicates particular information about the wearer (Howlett, Pine, Orakçığlu and Fletcher, 2002). For example, studies have supported that attire may be related to perceived professionalism and responsibility levels in the organisational context (Trautner and Kwan, 2010). This notion may also affect the perception of the $\mathrm{P}-\mathrm{O}$ fit of skilled professionals during the recruitment process, in that attire is linked to the level of responsibility of the job. For example, if a candidate is dressed in non-western attire at an interview, it can be perceived that the candidate may not suit senior job roles.

Religion can also influence an employer's evaluations of skilled immigrants during the recruitment and selection phase. According to Tubergen, Maas and Flap (2004, p. 722), immigrants from 'predominantly Christian countries participated more often in the labour market while discrimination tended to be stronger against non-Christian groups' in Western countries such as Australia, which then negatively influenced the non-Christian groups' labour market position. Prejudices and stereotypes towards religious groups may arise in the hiring process because RDM perceive that applicants' beliefs could threaten the smooth functioning of the organisation (Ghumman and Ryan, 2013). For instance, Ghumman and 
Jackson (2010) found that American Hijab-wearing Muslim women (Hijabis) were less likely to receive job offers than American Muslim women who do not wear the hijab.

Although existing research indicates the existence of discrimination against migrants from minority ethnic backgrounds based on their overtly visible identity, there is a lack of research on how organisational recruitment decision-makers' concern for fit may be influenced by their own lack of cultural capital, particularly their lack of understanding/competence of non-dominant cultures, non-dominant languages and religions due to their lack of experiences with diversity. Therefore, we aim to examine how RDMs cultural capital could influence their perception of SM candidates fit into the organisation during the hiring process.

\section{RESEARCH DESIGN AND METHODOLOGY}

The present research was conducted in two stages: a survey-based quantitative phase, followed by an interview-based qualitative phase.

\section{Stage 1: Survey-based quantitative phase}

The hypothesis of the stage 1 was as follows:

There will be a negative correlation between RDM level of understanding of culture and business (RDUCB) and their concerns for P-O fit of migrants (POFM) coming from diverse cultural backgrounds.

The quantitative survey was aimed at examining the relationship between RDM's level of understanding of diverse culture and business (RDUCB) and their concerns about P-O fit (POFM) of culturally diverse candidates in the selection process. 


\section{Sample}

A survey was conducted as part of a larger research study on skill use of migrants in the IT industry in New South Wales, Australia. The survey items were developed from a literature review and field interviews with HR managers and two senior HR academics.

The online survey questionnaire was sent to 6,500 HR professionals and line managers who were clients of a Sydney-based IT recruitment consulting company. The questionnaire was completed by 428 respondents, of which 304 participants completed all of the questions. The low response rate $(428 / 6500=6.5 \%)$ can be at least partially explained by the timing of the email (emails were sent during the summer break in Australia when many employees take leave), the seniority of the targeted respondents and the politically sensitive nature of the research topic, which can all be deterrents of survey participation (Greer, Chuchinprakarn, and Seshadri, 2000).

\section{Insert Table 1}

The respondents were identified as decision-makers in the recruitment process in their organisation. This included HR professionals and line managers in charge of recruiting for their divisions.

\section{Variables and measures}

The dependant variable is recruitment decision makers' P-O fit concerns (RDPOF) about particular ethnic groups. To measure this variable, we used the question 'My senior management team is likely to have concerns about the suitability of the following ethnic groups to fit into my organisational culture'. We used six different cultural groups: (South East Asians, Middle Eastern, Lebanese, Indian, Europeans, Chinese and listed 'other' where 
participants can insert text of any other ethnic group. These groups were selected after consultation with two senior HR specialists in NSW. The independent variable is the recruiters' level of understanding of culture and business (RDUCB) of six different groups. To measure this variable, we used the question 'Many of the decision-makers in my organisation have a high level of understanding of culture and business in' ' and listed Asia and Pacific, Middle East, Americas, Europe, India and China as the regions/countries. Each of these items was measured by a four-point Likert scale ( 1 being 'strongly disagree' and 4 'strongly agree').

\section{Data analysis}

Initially, we used t-tests to help gauge the differences in coefficients between decision makers with different levels of understanding of diverse cultures and business. Examination of skewness and Q plots were used as tests for normality, and Likert data was initially treated as interval. Levene tests were used to test equal variance between groups and the appropriate t-test results were then interpreted. However, the four-point Likert scale data may be treated as ordinal rather than interval. Mann-Whitney U (Wilcoxon Rank Sum) tests were also conducted on the same subgroups against the same set of dependent variables.

Both tests (the t-test and the Wilcoxon rank-sum) revealed almost identical significant differences, with the only variation being the degree of significance. When tests differed in significance, Wilcoxon rank-sum results were utilised, because they provide a more conservative measure of between-group differences. In order to examine the relationship between RDUCB and different ethnic groups, we conducted Spearman's correlational analyses. We used Spearman's correlations rather than Pearson's, because Likert data with fewer than five points is better treated as ordinal rather than interval. An 
alpha level set at $\alpha=0.05$ (two-tailed) was used as a measure of significance for all statistical tests.

\section{FINDINGS}

\section{Stage 1: Quantitative Phase}

We found that the RDMs level of understanding of culture and business of ethnic cultures was significantly and negatively correlated to their concerns about P-O fit of the different cultural groups of applicants, in the context of the recruitment and selection process. $\mathrm{H} 1$ is validated in each particular case except for Europeans. The relationship is particularly strong for South East Asians and Chinese cultures.

\section{Insert Table 2}

The results of the quantitative analysis triggered us to investigate the findings in greater depth through qualitative methods.

\section{RESEARCH DESIGN AND METHODOLOGY}

\section{Stage 2: Qualitative Phase}

Stage 1 of the research found that RDM's level of understanding of diverse culture and business was significantly and negatively correlated to their concerns about P-O fit of SM candidates, particularly candidates from non-western cultures. Therefore, the objective of stage 2 was to understand more in-depth 1) factors that influence the cultural capital deficiency of the RDM, and 2) how cultural capital deficiency (assumptions, values and attitudes about selection criteria in relation to diverse cultures) can influence RDM perception of P-O fit of SMs from non-dominant cultures during the recruitment process. Sample 
At the end of the quantitative survey, we asked the respondents if they would like to receive the summary of the findings and if so to provide an email address. After the quantitative data analysis, we sent a summary of our research findings to the 141 research respondents who had provided their email address. In that same email, we asked whether they were willing to be interviewed as an extension of the research to better understand the survey findings. Out of the 141 respondents 22 agreed by email to be interviewed. However, due to time constraints faced by the participants who were senior managers in IT sector, only 19 participants were interviewed. All interviewees were from medium to large organisations.

\section{Insert Table 3}

\section{Interview process}

We chose face-to-face interviews because they provide a greater degree of social interaction between the interviewers and the interviewees. The researchers recorded all interviews digitally. The researchers then transcribed the interviews and undertook a memo-writing exercise immediately following each interview to capture any additional information not recorded, as well as initial thoughts and ideas that might assist the subsequent analysis. In general, interviews lasted between forty-five and sixty minutes.

We used semi-structured interviews. The interview schedule included open-ended questions, and a probing technique was used to gain as much in-depth information as possible on our topic. Major questions included their role, personal background, exposure to people from diverse backgrounds, general recruitment experiences, particularly in relation to skilled migrants from minority ethnic backgrounds, stereotypes about people originating from various cultural backgrounds, the need for fit during the selection process, the 
candidate criteria and how the fit of the candidate is assessed. The questions aimed to shed light on 'the social processes of interaction that individuals within a culture implicitly know but those outside the culture do not' (Bluff, 2000, p. 115).

This approach allowed us to probe emerging themes and ensure the possibility of discovering insights beyond those identified by prior literature. The inductive approach reflects the exploratory nature of the study. The first three interviews were conducted by the first author, a first generation, NESB SIE to Australia and an Anglo-Australian research assistant. These three interviewees included individuals who were first generation migrants/SIEs to Australia. A sense of tacit camaraderie was built between the ethnic migrant interviewer and the migrant research participants based on their common migrant status. This common context enabled the participants to feel more comfortable to share their stories with another migrant.

The remainder of the interviews were conducted by the Anglo-Australian research assistant who had accompanied and observed the first three interviews. We were mindful that the Anglo-Australian research assistant was trained to ensure that both migrant and local research participants were comfortable to discuss sensitive and at times, politically sensitive topic areas.

\section{Data coding and data analysis}

Interview data analysis was done using manual coding. The coding was conducted iteratively. Each interview was initially independently coded by two researchers using open coding, followed by discussion of the coding results to assure consistency. Coding was only considered complete when a consensus on each construct was reached. In this analysis, researchers made connections between the codes of the data, and the themes found in the literature review. Particularly, the researcher attempted to make sense of the codes and 
quotes in relation to the cultural capital literature. The researcher also used mind mapping techniques using visual diagrams to understand the connections between variables.

\section{Insert Figure 1}

\section{FINDINGS}

\section{Stage 2- qualitative phase}

\section{Factors that influence RDMs cultural capital: Individual exposure to foreign cultures}

The interviewees' perception of the fit of particularly skilled migrant candidates from minority ethnic backgrounds into their organisations as employees depends on the level of exposure of the interviewees to those particular ethnic groups.

There is some real entrenched racism there. [I think it comes from] not being exposed and from their parents. I think it is still being passed on generation to generation even when there is exposure. I do know that more fair-minded people are changing around. - Interview 5

Interviewees said that having positive exposure or contact with people from minority groups could make a difference to the preconceptions of the decision-makers. Typically, one of the best forms of positive contact is achieved through their work in organisations.

I acquired a team and on that team were three Indians... An Aboriginal... A couple of Aussie guys and a couple of Brit guys... They were the really close-knit team... They learned how to respect each other. - Interview 14

When employers work closely with people of diverse backgrounds and origins, their stereotypes can dissipate and instead they are able to understand the similarities among them instead of only the differences (Frolund 2012). Similarly, positive work experiences and contact with skilled migrants from minority ethnic backgrounds can change negative perceptions the decision-makers may have of minority groups, originally due to their family background and level of education. 
One of my co-workers, I respected him, but I was appalled at some of his attitudes, especially towards blacks, but he was assigned to work with a couple of people of colour and then as he worked with them, I think he started realising his attitudes were out of place and unfair. I think his attitude evolved and he realised what he grew up with wasn't true. - Interview 5

The perception of fit of skilled migrants from minority ethnic backgrounds can also be reduced when an organisation has decision-makers who originate from a first or second generation migrant background. In such circumstances, they tend to have a more positive approach to immigrant candidates during recruitment and place less weight on stereotypes.

My parents are migrants to the country, so I've tended to side a lot more with those who are migrants. When I interview someone who is a recent migrant from wherever, I can sit down and break it down because I understand the story. But not many people are like that. - Interview 9

\section{Factors that influence RDMs cultural capital: Organisational cultural values}

Interviewed participants noted how organisational values can influence RDM cultural capital and their perception of PO fit during the selection process.

These days as we hire staff, particularly project management staff the first thing in mind is "how does this person fit in with this organization?" Will he or she be able to go and interact with the business outlines? This is where the culture comes in significantly because of the fact that... there is this implicit culture." Interview 1

Typically, larger organisations such as multinational corporations may already have an ethnically diverse group of employees and therefore, the majority of the employees working at such organisations would have higher levels of real life work experiences of working with ethnically diverse group of people working in their overseas divisions.

We are a multinational company and I think that plays into it a bit. So, we are quite open to that. Diversity is one of our corporate values as to make to we do make sure we recognize the right people and that does get applied. I think migrants are more open to different migrants. - Interview 8 
Further, due to their globalised operations and exposure to globalised clientele, it is possible that large multinational organisations would have a combination of host country, home country and third country nationals working within the company at various levels.

\section{RDMs assumptions, values and attitudes and its influence on P-O of fit of SMs into their organisations}

Many of the interviewees tended to highlight a particular set of assumptions and attitudes towards some key selection criteria including the candidate's communication skills, qualifications, work experiences and visible appearance (particularly their attire and religious affiliation). First, interviewed RDMs seem to exhibit stereotypes about some cultures and their communication style. Such stereotypes then can have an impact on their evaluation of the candidates $\mathrm{P}-\mathrm{O}$ during the recruitment process.

The Chinese can be a little more abrupt, but there is also a way of dealing with the Chinese, but I think after that they fit in quite well. I think some of the Middle Eastern cultures can be more aggressive than others. The Indian cultures can tend to just rave on about rubbish at 100 mile per hour. I think it's up to the individual in the company to refocus them. - Interview 10

Second, many of the interviewees tended to indicate that they have a preference for candidates who are locally educated. Perhaps this was a comfort factor as their values and attitudes were influenced by their own personal experiences and comfort level in knowing how to assess the local qualifications. When a candidate's educational background is foreign to the RDM then it can create a sense of discomfort as they have not had any experience of foreign education systems.

I think there is a preference for Australian education. I know if you've been to Macquarie uni, you can write, read, and communicate verbally in English. If that degree comes from somewhere else in the world, then it's something else to screen for before hiring. - Interview 8 
Again, just as the values and attitudes of RDM influenced their stereotyping of candidates from diverse cultures, they also held stereotypes about the value of education from particular countries. For example, interviewed participants seemed to value educational qualifications from Westerns countries and tended to undermine the quality of the educational qualifications from particular Asian regions.

I don't personally place too much value on universities, but there is a huge difference in university education between here, India, China, Europe- a massive difference. So if you're talking about software development, people love eastern Europeans, absolutely love them. The way they are educated is different. There are businesses in Sydney that actively recruit from companies over there [Russia, Latvia]. - Interview 19

Interestingly, an interviewed participant noted that values and attitudes were linked to the level of confidence and level of risk of the unknown. For example, if the candidate's education was undertaken in a country that the decision maker is less aware of, and have a minimum understanding of, then it is categorised as riskier investment for the organisation and thus considered a low P-O fit.

It comes down to the comfort factor in the person recruiting. They probably have a better understand or confidence in a local degree because it is a known quantity. Recruitment is a risk management exercise because it is a big investment for the company. If you have two candidates apparently equal in other ways, you will take the less risky option and knowing what you're getting is risk mitigation. Interview 6

Third, interviewed RDM also showcased similar values and attitudes towards how they assessed work experience of foreign candidates. Again, similar to education, if the work experiences of candidate were from a country that the decision-maker was unfamiliar with, then their perception of fit of the candidate was negatively influenced. The comparison of local versus international experiences, particularly work experiences that the RDM was not familiar with meant that such international experiences were devalued against the local work experiences. Thus, it seemed that 
RDM's knowledge and awareness of international work cultures had a significant influence on how they evaluated work experiences of candidate.

Overseas experience is an issue because it's unknown. If there is [sic] enough candidates with local experience, then those without it won't make it to the shortlist. - Interview3

Consequently, interviewed RDM note that they assumed local work experience indicated a better P-O fit than international work experience.

It will have a significant barring on it. At the end of the day, if there were 5 different candidates, someone without the local experience wouldn't get the preference. Local experience probably reflects more about their fit in an organization because if they worked in an organization locally, they have been exposed to the environment locally. - Interview 1

The reason RDM prefer local work experiences and education may be because they have limited understanding or exposure to the international education systems and work environments which limits their ability to gauge the standard in relation to the local education and work experiences. When there is a lack of knowledge or information on overseas qualifications and work systems, it is most likely that they will relatively devalue any international qualifications or experiences. Thus, the lack of experience and understanding of international education systems and work cultures can increase the perception of risk when recruiting non-local candidates. It is also possible that the general and industry based stereotyping and perceptions employers have regarding the quality and the value of qualifications and experiences from diverse countries can influence their views on the risk taken in hiring candidates from diverse cultural backgrounds.

Finally, interviewed RDMs also indicated some common attitudes towards candidate's appearance, particularly their attire and religious affiliation. Again, it seemed that interviewed participants tended to indicate that any visible symbols of a potential 
candidate that were incongruent with their own perception and values, were considered to have a low P-O-fit.

My personal opinion is that people are more accepting of a turban than they are of a headscarf. I don't think people like any overt, heavily religion either way. Interview 10

Such attitudes seemed to have been fuelled by the negative social pressure that was linked to terrorism and negative perceptions that Western societies may have about the appearance of persons linked to terrorism.

After 9/11 there is a bit of uncomfortableness with Islam, but not openly. There is a bit of a negative thing I would say. Consciously they might not be but unconsciously I think it will influence the decision if they have a negative connotation with that religion. - Interview 3

This is particularly a concern if their client base is mainly Caucasian or AngloAustralian.

If it is an issue for my customer, it has to be an issue for me. Again, it's a risk management exercise. If I was working in an organisation that was predominately Caucasian people and the culture was predominately Caucasian and I had to select someone who was going to represent me to the rest of that culture. Interview 6

Perhaps, these negative perceptions of Islamic attire are driven by the current negative media driven social biases about terrorism and its affiliation to Islam and the issues of refugees entering Western countries and the social challenges the western societies face due to the perceived differences (McMichael, 2017). Consequently, Islamic religious affiliations of a candidate can have a significant influence on the employer recruitment decision-making. Overtly expressed views and habits that illustrate one's religious affiliations could be used by employers to assess the candidate's suitability and fit to the organisation. The religious affiliation could be used as a factor that could determine whether the RDM could establish a trusting relationship with the candidate. 
According to Goffman (1963), persons with what are deemed to be controllable stigmas are often more likely to be branded due to the perception that they are responsible for their condition (see also Gneezy, List and Price, 2012). Many Muslim women who wear the hijab do not classify it as an obligation, thus being seen as a controllable condition. Controllable stigmas attract greater stigmatisation, which leads to unfavourable outcomes (Gneezy et al. 2012). Interviewees also expressed that a sense of distrust and distance occurs when particular individuals are perceived as forcing their faith on others or are perceived to be overtly outspoken about one's faith.

My take on that is everyone has different views and beliefs. I think though where someone... tries to force their own views and opinions on others, that's when people start to take more of an objection to it. - Interview 4

\section{DISCUSSION}

The aims of this study were to examine 1) how RDMs cultural capital can influence their concerns for P-O fit of SMs coming from diverse cultural backgrounds, 2) what factors influence the employers' level of cultural capital (understanding/competence of diverse cultures) and 3) how deficiency of cultural capital (assumptions, values and attitudes about selection criteria relevant to diverse cultures) can influence the recruitment decision making process and concerns about the fit of SMs who originate from non-western backgrounds.

As the survey data indicate, RDMs level of understanding of non-western culture and business had a negative impact on their perception of candidates from non-western backgrounds. Interview findings help to understand the factors that influenced such negative impact on their perceptions. There were organisational and individual level factors that influenced the cultural capital of the RDM. In terms of organisational level factors, the findings highlight how organisational cultural values and type of organisation can influence the decision-makers' perception of fit of candidates. In terms of individual factors, the findings indicate that the RDMs level of exposure to diverse cultures at work and at personal 
level can influence their assumptions and perception of the value of international educational qualifications and work experiences. Similarly, their personal and professional experiences can also influence their attitude and stereotypes about how they assess the perception of P-O fit based on a candidate's appearance and communication style.

Consequently, when RDM are less experienced in working with people who are different to them, they may be more likely to have a very specific set of values and attitudes that are considered acceptable and are aligned to their own behaviour and outlook. Particularly, the interview data indicate that this could have an unfavourable impact during the recruitment and selection process. We will next attempt to understand this by aligning the cultural capital of RDM to the resource based view.

\section{Cultural capital of RDM and its link to strategic resource decision-making}

The RBV focuses on resource heterogeneity as the potential source of differences in firm performance (Barney, 1991). Resources encompass the physical assets, intangible assets and organisational capabilities that are tied to firms (Barney, 1991; Hult, Ketchen and Slater, 2005). As a consequence, RBV traditionally seeks to develop the internal resources currently owned by an organisation (Wright, Dunford and Snell, 2001.p.703). Yet, some scholars argue that resources have only potential value and it is the firm's capacity to deploy or leverage resources that better explain performance differences between firms (Priem \& Butler, 2001a); Hult and Ketchen, 2007).

Resource management processes generally determine which human capital talent to be recruited, trained and used as capabilities to leverage market opportunities (Makadok, 2001). In terms of SMs, it is possible that RDMs may not see value in SMs as a capability or even a resource due to the differences in their cultural capital. On the other hand, decisionmakers who have a higher level of exposure to international businesses and culture and aim 
to exploit global market opportunities may be willing to perceive SMs as a resource capability. This approach can then influence their recruitment and retention practices and view on the value of SMs.

However, it is important to understand that stakeholders who are in charge of the resource acquisition and leveraging decision making may act as gatekeepers to keep SMs out of the resource pool of an organisation (Kraaijenbrink, Spencer, and Groen, 2010) (Kraaijenbrink, Spencer, \& Groen, 2010). This may be influenced by their decision making that looks at fit of the SMs into their existing resourcing and capabilities. As such the cognitive biases and judgements may hinder the stakeholders in charge of the resource acquisition and leveraging decision making (Garbuio, King and Lovallo, 2011). Perhaps this is influenced by the fact that individuals tend not to follow rational processes when they face complex choices between resources (Gabaix, Laibson, Moloche and Weinberg, 2006). Rather it may be easier to make decisions based on the stereotypes and biases from their past experiences of various talent pools (SMs versus skilled local candidates) and the organisational performance and fit (King, 2007).

RDMs with varying cultural capital and experiences may perceive different relationships between the value of SM talent and organisational resource capability and performance. These views may be greatly influenced by past, present and future contextual factors that influence recruitment and retention decision-making (Bateman and Zeithaml, 1989; Dirk, Carina and Jonas, 2010). Another factor that may influence resource decisionmaking is the over estimation of the value of existing organisational resources or talent pool (Garbuio et al., 2011). This may be because they are more familiar with the existing firm human capital talent (Prahad \& Bettis, 1986), have an aversion to the unknown, for instance non-western SMs who are most different to the local human capital (Garbuio, et al., 2011) and might anchor the resource acquisition/recruitment and resource allocation (retention 
leveraging decisions) based on the most recent resourcing decisions, due to the familiarity effect (Garbuio, et al., 2011)

\section{LIMITATIONS}

Although the study enabled more in-depth understanding of 1) how the cultural capital of RDMs can influence their assessment of migrant candidate $\mathrm{P}-\mathrm{O}$ fit during the selection process in Australia, and 2) the factors that influence the cultural capital of RDMs, there are several study limitations that must be acknowledged. First, the study sample was limited to the IT industry in the NSW region in Australia and they were self-selected based on their willingness to participate in the study. Second, the response rate for the survey was less than $10 \%$. However, the nineteen interviews shed further light on the survey findings, increasing the value of this approach. A reason for low response can perhaps be attributed to the sensitive nature of the topic; particularly issues related to discrimination which can cause participant hesitation and concern. Thus, we can only treat the data as exploratory or tentative until more authoritative studies can be undertaken. Finally, only one participant/decision maker was female. Although this is a characteristic of the male dominated IT industry, we still need to acknowledge the possibility of gender biased responses.

\section{CONCLUSION}

The study highlights a significant issue relating to the level of cultural capital of RDMs and its influence on their perception of person organisation fit of candidates. Some of the key factors that influenced P-O fit of RDM include organisational cultural values, decisionmakers' experiences with diversity and the resulting assumptions, values, and attitudes. Organisations need to be mindful about developing the internal resource capabilities to compete globally and thus develop their internal resources, particularly of the decision- 
makers in the organisation. As such, it is important that employers have strategic crosscultural training and diversity management policies in place, which move beyond mere 'window dressing' to impact on the attitudes and values of those within workplaces (Bezrukova, Spell, Perry, and Jehn, 2016).

\section{REFERENCES}

Al Ariss, A., and Syed, J. 2011 "Capital Mobilization of SMs: A Relational Perspective", British Journal of Management, 22: 286-304.

Al Ariss, A., and Crowley-Henry, M. 2013 "Self-initiated expatriation and migration in the management literature", Career Development International, 18(1): 78-96.

Australian Bureau of Statistics 2011 "Trends in Migration: Australia 2010-11”. Available at: https://www.border.gov.au/ReportsandPublications/Documents/statistics/trends-inmigration-2010-11.pdf_accessed 20 November 2015.

Barney, J. B. 1991 "Firm resources and sustained competitive advantage", Journal of Management, 17: 99-120.

Barney, J. B. \& Arikan, A. M., 2017 "The Resource Based View". in: H. A. Michael, E. F. R \& H. S. Jeffrey, (Eds), The Resource-based View, Wiley Online Library.

Bateman, T. S., and Zeithaml, C. P. 1989 "The psychological context of Strategic Decisions: A model and convergent experimental findings", Strategic Management Journal, 10: $59-74$

Bezrukova, K., Spell, C.S., Perry, J.L., and Jehn, K.A. 2016 "A meta-analytical integration of over 40 years of research on diversity training evaluation", Psychological Bulletin, 142(11): 1227.

Bourdieu, P. 1986 "The forms of Capital", in: J. Richardson (Ed.), Handbook of Theory and Research for the Sociology of Education, Connecticut: Greenwood Press: 46-58. 
Bourdieu, P. 1990 The Logic of Practice, Stanford University Press.

Bourdieu, P. 2010 Distionction: a social critique of the judgement of taste. Nice R, translator. Oxford: Taylor \& Francis Ltd: 610.

Bluff, R. 2000 "Grounded theory”, in Cluett E. and Bluff R. (Eds.), Principles and Practice of Research in Midwifery, Edinburgh, Bailliere Tindall: 113-130.

Cameron, R. 2011 “Responding to Australia's regional skill shortages through regional skilled migration", Journal of Economic and Social Policy, 14(3) : 46-80.

Chaloff, J., and Lemaitre, G. 2009 "Managing highly-skilled labour migration: A comparative analysis of migration policies and challenges in OECD countries", $O E C D$ Social, Employment and Migration Working Papers, Directorate for Employment, Labour and Social Affairs, Paris, available at http://www.oecd.org/els/mig/46656535.pdf.

Doherty, N., and Dickmann, M. 2009 "Exposing the symbolic capital of international assignments", The International Journal of HUman Resource Management, 20(2): 301-320.

Dirk, H., Carina, B. F., and Jonas, F. P. 2010 "Recruitment and Retention in Foreign Firms in India: A Resource Based View", Human Resource Management, 49(3): 439-455.

Erel, U. 2010 Migrating cultural capital: Bourdieu in migration studies, The Open University, 44(4): 642-660.

Frolund Thomsen, J. 2012 "How does Intergroup Contact Generate Ethnic Tolerance? The Contact Hypothesis in a Scandinavian Context", Scandinavian Political Studies, 35(2): 159-178.

Gabaix, X., Laibson, D., Moloche, G., and Weinberg, S. 2006 "Costly information acquisition: Experimental analysis of a boundedly rational model", American Economic Review, September, 96(4): 1043-1068. 
Garbuio, M., King, A. W., and Lovallo, D. 2011 "Looking inside: Psychological influences on structuring a firm's portfolio of resources", Journal of Management, 37: 14441463.

Greer, T., Chuchinprakarn, N., and Seshadri, S. 2000 'Likelihood of Participating in Mail Survey Research: Business Respondents' Perspectives", Industrial Marketing Management, 29: 97-109.

Ghumman, S., and Ryan, A. 2013 "Not welcome here: Discrimination towards women who wear the Muslim headscarf', Human Relations, 66: 671-698.

Ghumman, S., and Jackson, L. 2010 "The downside of religious attire: The Muslim headscarf and expectations of obtaining employment", Journal of Organizational Behavior, 31: 4-23.

Gneezy, U., List, J., and Price, M.K. 2012 Toward an understanding of why people discriminate: Evidence from a series of natural field experiments (No. w17855). National Bureau of Economic Research.

Goffman, E. 1963 Stigma: Notes on the management of spoiled identity, Prentice Hall, New York.

Guo, C., and Al Ariss, A. 2015 "Human resource management of international migrants: Current theories and future research:, The International Journal of Human Resource Management, 26(10): 1287-1297.

Hebbani, A., and Colic-Peisker, V. 2012 "Communicating one's way to employment: A case study of African settlers in Brisbane, Australia", Journal of Intercultural Studies, 33(5): 529-547.

Howlett, N., K., Pine, I., Orakçığlu, and Fletcher, B. 2002 “The influence of clothing on first impressions: Rapid and positive responses to minor changes in male attire”, Journal of Fashion Marketing and Management, 17( 1): 38-48. 
Hult, G. T. M., and Ketchen, D. J. 2007 "Strategic supply chain management: Improving performance through a culture of competitiveness and knowledge development", Strategic Management Journal, 28(10): 1035-1052.

Hult, G. T. M., Ketchen, D. J., and Slater, S. F. 2005 "Market orientation and performance: An integration of disparate approaches", Strategic Management Journal, 26(12): 1173-1181.

Ibarra, H. 2003 Working Identity: Unconventional Strategies for Reinventing Your Career, Harvard Business School Press.

King, A. W., 2007 "Disentangling interfirm and intrafirm causal ambiguity: A conceptual model of causal ambiguity and sustainable competitive advantage", Academy of Management Review, 32(1): 156-178.

Kraaijenbrink, J., Spencer, J. -C., and Groen, A. J. 2010 "The resource-based view: A review and assessment of its critiques", Journal of Management, 36(1): 349-372.

Kristof, A. 1996 "Person- organization fit: An integrative review of its conceptualization, measurement, and implications", Personnel Psychology, 49: 1-49.

Korostelina, K. V. 2016 Trump Effect, Routledge.

Kostenko, W., Harris, M., and Zhao, X. 2012 “Occupational transition and country-of-origin effects in the early stage occupational assimilation of immigrants: some evidence from Australia”, Applied Economics, 44: 4019-4035.

Makadok, R. 2001 "Toward a synthesis of the resource-based and dynamic-capability views of rent creation", Strategic Management Journal, 22(5): 387-401.

McMichael, J. 2017 Preferring Refugees: How German Attitudes Changed During the European Refugee Crisis and Along Historical State Divides, Honours Thesis, Duke University, Durham, North Carolina. 
Nakhaie, M. R., and Kazemipur, A. 2013 "Social capital, employment and occupational status of the new immigrants in Canada", Migration \& Integration, 14: 419-437.

Özbilgin, M., and Tatli, A. 2005. "Understanding Bourdieu's contribution to management and organization studies", Academy of Management Review, 30: 855-869.

Pfeifer, S., Sarlijia, N., and Zekic, S. M. 2014 "Shaping the entrepreneurial mindset: entrepreneurial intentions of business students in Croatia", Journal of Small Business Management, 54(1): 102-117.

Prahad, C., and Bettis, R. 1986 "This may be because they are more familiar with the existing firm human capital talent", Strategic Management Journal, 7: 485-501.

Priem, R., and Butler, J. 2001a "Is the resource-based "view" a useful perspective for strategic management research?", Academy of Management Review, 26(1): 22-40.

Sacco, J., Scheu, C., Ryan, A., and Schmitt, N. 2003 “An investigation of race and sex similarity effects in interviews: A multilevel approach to relational demography", Journal of Applied Psychology, 88(5): 852-865.

Trautner, M., and Kwan, S. 2010 "Gendered appearance norms: An analysis of employment discrimination lawsuits, 1970-2008”, Research in the Sociology of Work,20: 127-150.

Tubergen, F., Maas, I., and Flap, H. 2004 "The economic incorporation of immigrants in 18 Western societies: Origin, destination and community effects", American Sociological Review, 69(5): 704-727.

Waxin M-F., and Panaccio A-J. 2010 “HRM case study: diversity management: facilitating diversity through the recruitment, selection and integration of diverse employees in a Quebec bank", Journal of International Academy For Case Studies, 16(4): 27-40.

Wright, P. M., Dunford, B. B. , and Snell, S. A. 2001 "Human resources and the resource based view of the firm", Journal of Management, 27: 701-721. 
TABLE 1

DESCRIPTION OF THE PARTICIPATING ORGANISATIONS (N=304)

\begin{tabular}{|lll|}
\hline Number of employees in Organisation & Frequency (n) & Percentage (\%) \\
\hline $1-50$ & 54 & 17.8 \\
$51-100$ & 21 & 6.9 \\
$101-500$ & 41 & 13.5 \\
$500+$ & 188 & 61.8 \\
Total & 304 & 100 \\
\hline
\end{tabular}

TABLE 2

\section{CORRELATIONS BETWEEN RECRUITER'S LEVEL OF UNDERSTANDING OF CULTURE AND BUSINESS AND THEIR CONCERNS ABOUT P-O FIT OF MIGRANTS}

\begin{tabular}{|c|c|c|c|c|c|}
\hline $\begin{array}{l}\text { Concerns about } \\
\text { fit of cultural } \\
\text { groups }\end{array}$ & \begin{tabular}{|l} 
Correlation \\
coefficient/ \\
$P$-value/ \\
Sample \\
size
\end{tabular} & $\begin{array}{l}\text { RDUCB } \\
\text { in Asia and } \\
\text { Pacific (A) }\end{array}$ & $\begin{array}{l}\text { RDUCB } \\
\text { in India }(\mathrm{E})\end{array}$ & $\begin{array}{l}\text { RDUCB } \\
\text { in China }(F)\end{array}$ & $\begin{array}{l}\text { RDUCB } \\
\text { Average of } \\
\mathbf{A}, \mathbf{E}, \mathbf{F}\end{array}$ \\
\hline \multirow{3}{*}{$\begin{array}{l}\text { South East } \\
\text { Asian }\end{array}$} & Correlation & $-.275^{* *}$ & $-.149^{* * *}$ & $-.192^{* *}$ & $-.246^{* *}$ \\
\hline & $\begin{array}{l}\text { Coefficient } \\
n \text {-value }\end{array}$ & 000 & 010 & $0 \cap 1$ & $0 \cap 0$ \\
\hline & $\mathrm{N}$ & 304 & 304 & 304 & 304 \\
\hline \multirow[t]{3}{*}{ Middle Eastern } & $\begin{array}{l}\text { Correlation } \\
\text { Coefficient }\end{array}$ & $-.181^{* *}$ & -.104 & $-.154^{* *}$ & $-.184^{* *}$ \\
\hline & $p$-value & .002 & .070 & .007 & .001 \\
\hline & $\mathrm{N}$ & 304 & 304 & 304 & 304 \\
\hline \multirow[t]{3}{*}{ Lebanese } & $\begin{array}{l}\text { Correlation } \\
\text { Coefficient }\end{array}$ & $-.203^{* *}$ & $-.130^{*}$ & $-.127^{*}$ & $-.187^{* *}$ \\
\hline & $p$-value & .000 & .024 & .027 & .001 \\
\hline & $\mathrm{N}$ & 304 & 304 & 304 & 304 \\
\hline \multirow[t]{3}{*}{ Indian } & $\begin{array}{l}\text { Correlation } \\
\text { Coefficient }\end{array}$ & $-.203^{* *}$ & $-.131^{*}$ & $-.121^{*}$ & $-.181^{* *}$ \\
\hline & $p$-value & .000 & .023 & .035 & .002 \\
\hline & $\mathrm{N}$ & 304 & 304 & 304 & 304 \\
\hline \multirow[t]{3}{*}{ Europeans } & $\begin{array}{l}\text { Correlation } \\
\text { Coefficient }\end{array}$ & $-.140^{*}$ & .021 & -.008 & -.070 \\
\hline & $p$-value & .015 & .712 & .885 & .221 \\
\hline & $\mathrm{N}$ & 304 & 304 & 304 & 304 \\
\hline \multirow[t]{3}{*}{ Chinese } & Correlation & $-.271^{* *}$ & $-.151^{* *}$ & $-.190^{* *}$ & $-.247^{* *}$ \\
\hline & $p$-value & .000 & .008 & .001 & .000 \\
\hline & $\mathrm{N}$ & 304 & 304 & 304 & 304 \\
\hline
\end{tabular}

Note: $*$ and $* *$ indicate that the corresponding null hypothesis is rejected at the 10 and 5 per cent level of significance, respectively. 
TABLE 3

INTERVIEWEES CHARACTERISTICS (N=19)

\begin{tabular}{|l|llll|}
\hline Gender & Migrant & \multicolumn{1}{c|}{ Anglo/Non-Anglo } & Role & $\begin{array}{l}\text { Interview } \\
\text { number }\end{array}$ \\
\hline Male & Yes & Anglo (American) & Line Manager & 5 \\
Male & No & Anglo (Australian) & Line Manager & 6 \\
Male & Yes & Minority ethnic background & Line Manager & 8 \\
Male & Yes & Anglo & Line Manager & 16 \\
Male & Yes & Anglo (French) & Line Manager & 17 \\
Male & Yes & Anglo & Line Manager & 18 \\
Male & No & Anglo (Australian) & Line Manager & 7 \\
Male & Yes & Anglo (South African) & Line Manager & 19 \\
Male & Yes & Minority ethnic background & Line Manager & 3 \\
Male & Yes & Anglo (Russian) & Line Manager & 2 \\
Male & Yes & Minority ethnic background & Line Manager & 1 \\
Male & No & Anglo (Australian) & HR Professional & 4 \\
Male & Second gen & Minority ethnic background & HR Professional & 9 \\
Male & No & Anglo & Line Manager & 10 \\
Male & Yes & Anglo (French) & HR Professional & 11 \\
Male & Yes & Anglo (South African) & Line Manager & 15 \\
Male & Yes & Anglo (Irish) & HR Professional & 12 \\
Female & No & Anglo (Australian) & Line Manager & 13 \\
Male & No & Anglo (Australian) & HR Professional & 14 \\
\hline
\end{tabular}




\section{FIGURE 1}

SAMPLE OF CODING, THEMES AND CATEGORIES

Sub theme
Decision-maker experiences with diversity,
international cultures, education system
and business

Code - personal experiences (Sample interview quotes from interviewee 5)

Code - family background (Sample interview quotes from interviewee 19)

Code - work experiences (Sample interview quotes from interviewee 14)

\author{
Sub theme \\ Organisational culture
}

Code - cultural values/match

(Sample interview quotes from interviewee 1,6 )

Code - Type of organisation and size (Sample interview quotes from interviewee 8)
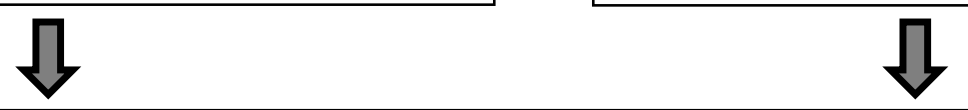

Category: Decision-makers' level of cultural capital

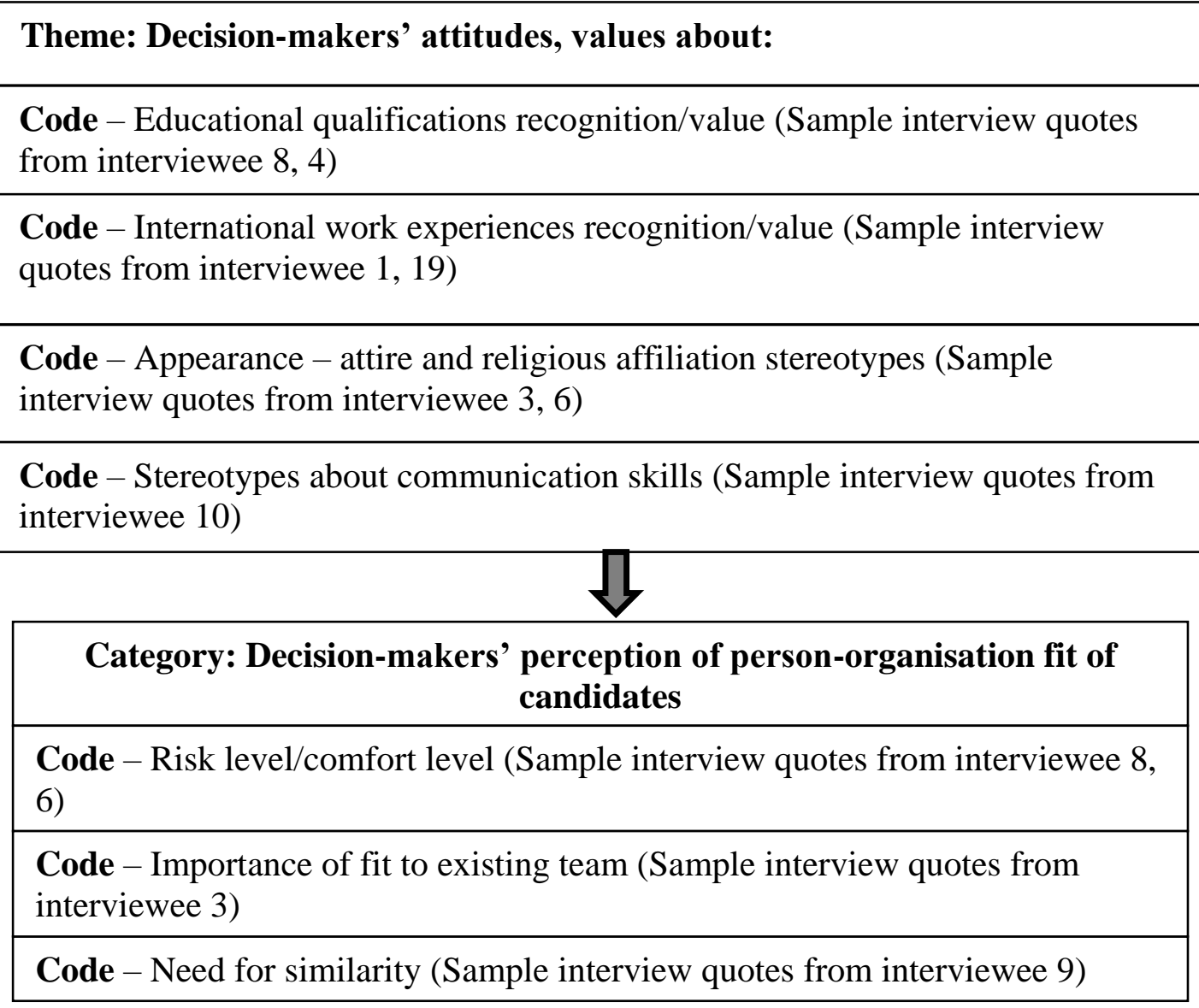

